\title{
HesitaÇÕes NA ARITMÉtica DE FREGE
}

\author{
Fernando Ferreira ${ }^{1}$
}

Em 1884, Gottlob Frege fecha a introdução d'Os Fundamentos da Aritmética com a formulação de três princípios fundamentais:

(1) É necessário separar com nitidez o que é psicológico do que é lógico, o que é objetivo do que é subjetivo.

(2) Só se pode perguntar pela denotação de uma palavra no contexto de uma proposição e não considerando-a isoladamente.

(3) Deve manter-se sempre presente a distinção entre conceito e objeto.

Estas três injunções metodológicas estão na base do programa logicista de Frege de redução da aritmética à lógica. Estão mesmo na base do surgimento da filosofia analítica.

O volume d'Os Fundamentos da Aritmética é hoje considerado uma obra-prima da filosofia. Contém, numa primeira parte, críticas às opiniões de filósofos e matemáticos da época acerca da noção de número e termina com a exposição duma nova tese para a fundamentação da aritmética. Não obstante, esta é uma obra essencialmente programática e pouco amadurecida. O próprio Frege afirma n'Os Fundamentos da Aritmética que não fez nada "mais do que ter tornado verosímil a natureza analítica das proposições aritméticas" e adianta que dúvidas quanto à natureza puramente lógica dos raciocínios expostos apenas podem ser dissipadas "por meio de uma apresentação de uma cadeia dedutiva sem lacunas". O magnum opus de Frege são os dois tomos das Grundgesetze der Arithmetik (Leis Fundamentais da Aritmética), publicados com um intervalo de dez anos, em 1893 e 1903. Nesta obra, Frege leva a cabo o programa logicista nos termos com os quais se achava comprometido, i.e., por meio de deduções estritamente formais. Para o fazer, Frege socorre-se do seu anterior trabalho Begriffsschrift (Notação Conceptual) de 1879. Na nossa opinião, a grandeza imorredoura de Frege encontra-se precisamente nesta obra precoce. De uma assentada, Frege faz nesta obra duas contribuições geniais. Em primeiro lugar, inventa uma linguagem formal para a quantificação, em que os quantificadores podem aparecer encadeados. Depois, oferece-nos um cálculo formal para efetuar deduções nesta linguagem (o cálculo de predicados).

É bem certo que se pode pôr em causa a importância que Frege dá a formalizar completamente os raciocínios da sua dedução lógica da aritmética. Hoje em dia, muitos argumentarão que isso não é essencial e que, de facto, é a própria informalidade d'Os Fundamentos da Aritmética que a torna uma obra acessível, conhecida e lida. Também eu partilho desta opinião. Porém, não se deve passar em claro as enormes consequências involuntárias que a opção fregiana teve. As linguagens de programação são linguagens formais e podem ser consideradas herdeiras afastadas da visão fregiana. Mais próximo das preocupações de Frege, o Begriffsschrift é o primeiro sistema formal dedutivo depois do cálculo silogístico aristotélico, ultrapassando-o vastamente em poder expressivo. Com

\footnotetext{
${ }^{1}$ Departamento de Matemática, Faculdade de Ciências, Universidade de Lisboa. Email: fjferreira@fc.ul.pt.

DOI : 10.21452/LnA_serie_n_v01_book_seminario-logica-no-aviao-2013-2018_fernando-ferreira_p.22-28
} 
efeito, o cálculo de predicados é capaz de formalizar axiomaticamente a prática matemática, o que deu origem à disciplina da Lógica Matemática e aos estudos metamatemáticos. No âmbito da Lógica Matemática estas formalizações ocorrem, em grande parte, como formalizações em princípio. Porém, com o aparecimento recente dos assistentes de demonstrações ("proof assistants"), a visão fregiana do rigor, no seu sentido mais estrito, encontrou o seu herdeiro natural e do qual - tenho essa convicção - ainda se vai ouvir falar muito nas próximas décadas.

Afirmei acima que Os Fundamentos da Aritmética é uma obra pouco amadurecida. Tal não obsta a que se encontre n'Os Fundamentos da Aritmética grandes ideias e análises, de que são exemplos a defesa de que o número se aplica a um conceito ou o esboço da dedução lógica das leis fundamentais da aritmética a partir do princípio de Hume. Porém, em certas alturas cruciais, a obra é surpreendentemente hesitante e ambígua, oscilando fortemente entre posições incompatíveis. Frege acaba por não fazer uso direto da segunda injunção para explicar a apreensão de números, ainda que esta injunção esteja sempre presente como um espectro no logicismo d'Os Fundamentos da Aritmética. Por outro lado, se bem que a terceira injunção seja sempre mantida na forma, ela não é mantida na substância e isso veio a revelar-se fatal por causa do paradoxo de Russell.

Gostaria de terminar este introito com uma observação pouco habitual. Um leitor de Frege, mesmo que não muito atento, não deixará de notar o modo mordaz com que por vezes Frege critica posições rivais. Esta forma de proceder deixou marca nefasta nalguma prática da filosofia analítica, traduzindo-se ocasionalmente por certas formas pouco corteses de criticar posições adversárias. Também, aqui e ali, levou a um estilo de filosofar muito apoiado no bon mot em prejuízo duma sobriedade distanciada. Não está em causa o facto de Frege ter razão na grande maioria das críticas que fazia, mas o tom e a insistência com que as fazia provavelmente gerava algum desconforto e, certamente, não ajudou a que o seu trabalho fosse justa e devidamente apreciado mais cedo.

N'Os Fundamentos da Aritmética, Frege propõe uma nova forma de explicar o acesso epistemológico a objetos abstratos. Tomemos o próprio exemplo de Frege da direção duma reta. Dada uma reta $\ell$, o termo "a direção da reta $\ell$ " denota um objeto autónomo. Isto não requer, no entanto, que se tenha de dar uma denotação a este termo quando ele é considerado isoladamente. De acordo com a segunda injunção fregiana, apenas temos de responder pela denotação duma expressão no contexto duma proposição. Frege elege as igualdades entre direções como caso paradigmático destas proposições. De acordo com Frege, ao utilizarmos termos como "a direção da reta $\ell$ ", temos de estar na posse dum critério que permita afiançar se esse termo denota o mesmo objeto que outro termo do mesmo género. É claro que possuímos esse critério e ele é o seguinte: a direção da reta $\ell$ é igual à direção da reta $r$ se, e somente se, $\ell$ e $r$ são retas paralelas.

O critério acima estabelece, nas palavras de Frege, "o conteúdo de um juízo de reconhecimento" e marca uma forma de abstracionismo que se harmoniza muito naturalmente com as três injunções fregianas. A segunda injunção, como vimos, desempenha um papel crucial na própria formulação deste abstracionismo. Por outro lado, ao evitar considerar expressões do género "a direção da reta $\ell$ ", tomadas isoladamente, não caímos na tentação de invocar representações subjetivas de direções ou de apelar a uma intuição de direções. O critério fregiano de igualdade é puramente objetivo. A primeira injunção é, portanto, 
cumprida escrupulosamente. Finalmente, Frege não define a direção da reta $\ell$ como sendo o conceito "ser uma reta paralela à reta $\ell$ ". Para Frege, as direções são objetos e (de acordo com a terceira injunção) devemos ter sempre presente a distinção entre conceito e objeto. Uma direção não é um conceito.

Todavia, a situação da teoria abstracionista de Frege n' Os Fundamentos da Aritmética é ambígua e problemática. Ainda que Frege chame com frequência a atenção para os juízos de reconhecimento, acaba por não subscrever o abstracionismo que os torna tão centrais. Diria que Frege gosta deste abstracionismo, que o acha uma muito boa ideia, mas que finalmente - renuncia a ele a contragosto. Renuncia a ele umas poucas páginas depois de o ter introduzido. A (auto)crítica é contundente. Não basta ter maneira de determinar quando é que as igualdades da forma "a direção da reta $\ell$ é igual à direção da reta $r$ " são verdadeiras para que, automaticamente, tenhamos um método para determinar o valor de verdade de todas as proposições em que ocorram termos do género "a direção da reta $\ell$ ". É também necessário que se dê um método para determinar o valor de verdade das proposições da forma "a direção da reta $\ell$ é igual a $t$ ", onde $t$ é um termo (denotando um objeto) não necessariamente do género "a direção da reta $r$ ". Frege põe a questão da seguinte maneira: como é que sabemos "se a Inglaterra é o mesmo que a direção do eixo da Terra"? A pergunta parece estapafúrdia mas, de facto, revela uma grande finura lógico/filosófica por parte de Frege. Ninguém iria confundir a Inglaterra com a direção do eixo a Terra, mas a distinção não se explica a partir do critério da igualdade de direções. "Falta-nos o conceito de direção", afirma Frege e, é claro, anda-se em círculo se dissermos que $t$ é uma direção se $t$ for a direção dalguma reta. Este problema é hoje conhecido por problema do Júlio César pois, n'Os Fundamentos da Aritmética, Frege pergunta "se este conhecido conquistador da Gália é ou não um número".

Chegado a este ponto, Frege tenta outro caminho. Define agora as direções explicitamente (e não através de proposições de reconhecimento): a direção da reta $\ell$ é a extensão do conceito "ser uma reta paralela à reta $\ell$ ". Frege renuncia aqui ao uso direto da segunda injunção. Agora já se sabe qual é o sentido da expressão "a direção da reta $\ell$ ", tomada isoladamente: é a extensão do conceito "ser uma reta paralela à reta $\ell$ ". Frege não se alonga sobre a noção de extensão, apenas a discutindo por duas ou três vezes n' Os Fundamentos da Aritmética. Diz primeiramente, numa nota de pé de página, que extensões são objetos e que pressupõe que saibamos o que é uma extensão. Esta suposição não é discutida n' $O s$ Fundamentos de Aritmética podendo-se, contudo, imaginar que Frege apenas dá sentido a expressões do género "a extensão do conceito $F$ " através da segunda injunção. Talvez seja esse o caso, como discutiremos mais tarde.

Quando se lê Os Fundamentos da Aritmética, fica-se com a sensação de que a solução encontrada - por meio de extensões - não satisfaz Frege plenamente. É instrutivo citar Frege mais longamente, agora na última vez em que discute a noção de extensão nessa obra: "[...] pressupusemos como conhecido o sentido da expressão 'extensão do conceito'. Esta maneira de ultrapassar a dificuldade [...] não encontrará, é certo, aplauso unânime e muitos preferirão [...] outro processo. Eu também não atribuo qualquer peso decisivo à participação nela da extensão de um conceito". A posição de Frege é vacilante. Talvez isso explique por que razão é que, na nota de pé de página atrás referida, Frege sugere com uma enorme ligeireza - um caminho alternativo, sem extensões, em que propõe que se considere que a direção da reta $\ell$ seja o conceito "ser uma reta paralela à reta $\ell$ " (de facto, esta proposta é feita para números - não direções - mas isto é incidental). Frege 
faz uma afirmação destas em flagrante contradição com o que defendia pouco antes. Se bem que seja verdade que Frege relembre nessa mesma nota de pé de página as objeções contra tomar direções (e números) como conceitos, acaba por afirmar candidamente que "embora eu seja da opinião de que [...] as objeções podem ser refutadas, isso iria aqui levar-nos demasiado longe". Esta é, talvez, a nota de pé de página mais momentosa de toda a história da filosofia analítica ...

Para Frege, o problema fundamental da aritmética é este: "como é que apreendemos objetos lógicos e, em particular, os números?" Acima, focámo-nos em direções em vez de números pois isso facilitou a discussão de certas questões. Numa recapitulação do que foi feito n'Os Fundamentos da Aritmética, Frege escreve que "só seguindo este princípio [segunda injunção], penso eu, se pode evitar a conceção fisicalista do número sem se cair na conceção psicológica do mesmo". Para Frege, os números aplicam-se a conceitos. Por exemplo, o número 1 aplica-se ao conceito "ser satélite natural da Terra". Noutra maneira de dizer: para o conceito "ser satélite natural da Terra" vem o número 1. A cada conceito está associado o número que vem para ele, tal como a cada reta está associada a sua direção. A expressão "o número que vem para o conceito $F$ " denota um objeto mas tal não requer que se tenha que dar uma denotação a este termo quando ele aparece isoladamente. A denotação destes termos é, de acordo com Frege, dada através do contexto de juízos de reconhecimento. O critério de igualdade para os números é conhecido como o princípio de Hume: o número que vem para o conceito $F$ é igual ao número que vem para o conceito $G$ se, e somente se, os conceitos $F$ e $G$ são equinuméricos. Neste critério, a noção de equinumericidade entre conceitos é a noção, hoje familiar, da existência duma bijeção entre os objetos que caem sob $F$ e aqueles que caem sob $G$.

Como se disse na secção anterior, Frege renuncia a esta forma de abstracionismo por causa do problema do Júlio César. Porém, há algo que parece ter escapado a Frege pois há um problema adicional com este abstracionismo. Há uma circularidade subtil no critério de reconhecimento para números dado pelo princípio de Hume. Com efeito, na formulação da equinumericidade de conceitos ocorre o sinal de igualdade: ocorre, obviamente, na própria formulação do que é ser uma bijeção, mas também pode ocorrer na expressão sintática dos conceitos em causa. Ora, se estivermos a contar números, p. ex., a considerar a igualdade numérica entre o número que vem para o conceito "ser um número primo menor do que 15" e o número que vem para o conceito "ser um divisor de 12", a formulação de que estes dois conceitos são equinuméricos (a de que há uma bijeção entre os objetos - números - que caem sob um e outro conceito) envolve igualdades entre números. Ora estas igualdades, pace o problema do Júlio César, devem ser explicadas pelo critério de igualdade que advém do princípio de Hume. Há aqui um círculo que não existe no caso das direções.

Uma forma de evitar esta circularidade seria impor que somente se façam contagens de objetos físicos, ou seja, que apenas se considerem equinumericidades entre conceitos que se aplicam a objetos físicos. Esta seria, claramente, uma solução ad hoc pois para Frege todos os objetos podem ser contados, inclusive os próprios números. Mas o caso é ainda mais sério pois esta solução não é adequada aos propósitos de Frege: se não for permitido contar números, o desenvolvimento fregiano da aritmética fica tecnicamente impossível de fazer. 
N'Os Fundamentos da Aritmética, Frege acaba por dar a seguinte definição explícita de número: o número que vem para o conceito $F$ é a extensão do conceito "ser equinumérico ao conceito $F$ ". É de observar que esta definição mostra, uma vez mais, que a posição de Frege n'Os Fundamentos da Aritmética ainda não estava totalmente amadurecida. Com efeito, Frege fala duma extensão cujos elementos são conceitos, nomeadamente aqueles conceitos que são equinuméricos ao conceito dado F. Mais tarde, nas Grundgesetze der Arithmetik, Frege já não se exprime assim. Nesta obra, as extensões são sempre extensões constituídas por objetos. O número que vem para o conceito $F$ é agora definido como a extensão do conceito "ser uma extensão dum conceito equinumérico ao conceito $F$ ".

IV

Nas Grundgesetze der Arithmetik deixa de haver hesitações sobre qual é o motor do logicismo. É, notoriamente, a existência de cursos de valores (Werthverlaufe) de funções. Frege é cristalino no prefácio das Grundgesetze der Arithmetik: "sem [cursos de valores] não conseguiríamos ser bem sucedidos".

Frege formula a sua famosa lei básica (V): o curso de valores da função $f$ é igual ao curso de valores da função $g$ se, e somente se, $f$ e $g$ têm o mesmo valor para todo os argumentos (objetos). As extensões de conceitos são um caso particular de cursos de valores pois, para Frege, um conceito é tão somente uma função cujos valores são o verdadeito e o falso (que, para Frege, são dois objetos distintos). Evidentemente, a lei básica (V) tem a mesma forma do príncipio de Hume. Ora, está vedado a Frege justificar a lei básica $(\mathrm{V})$ como um princípio de abstração pois isso seria simplesmente deslocar o problema do Júlio César dos números para os cursos de valores (extensões).

Frege está ciente do problema de que a lei básica (V) não determina a denotação dos cursos de valores e levanta a questão "Agora, como é que se resolve esta indeterminação?" Há uma tentativa de responder a esta interrogação nas Grundgesetze der Arithmetik mas - de modo nada característico para Frege - é muito pouco claro aquilo que é feito. Suponho que se tenta fixar o valor de verdade das proposições exprimíveis no sistema formal das Grundgesetze der Arithmetik. Em termos fregianos, tenta-se fixar a denotação daqueles nomes próprios que referem o verdadeiro ou o falso (nomes que exprimem pensamentos, na terminologia de Frege). Dada a ênfase na determinação (dos valores de verdade) destes nomes próprios de carácter proposicional, reconhece-se (talvez) nesta estratégia a segunda injunção. Contudo, a tentativa é defeituosa. Ela falha. O problema não está (somente) numa sub-determinação das denotações das expressões. Jaz, desgraçadamente, também numa sobre-determinação: a denotação da expressão que corresponde à proposição paradoxal russelliana é, simultaneamente, o verdadeiro e o falso.

Há pelo menos duas passagens nas Grundgesetze der Arithmetik em que Frege manifestou uma preocupação com a existência de cursos de valores. Numa passagem tardia, já no segundo volume, a discussão ocorre no âmbito duma crítica de Frege às denominadas definições criativas. Para Frege, o matemático nada cria e, neste aspecto, é como o geógrafo, limitando-se a mapear o que existe. Frege já o tinha referido n'Os Fundamentos da Aritmética e é instrutivo citar esta passagem: "O matemático, tal como o geógrafo, não pode criar arbitrariamente; também ele não pode senão descobrir o que já existe e atribuir-lhe um nome". Contra isto "pode ser apontado que [...] nós próprios criámos objetos, nomeadamente os cursos de valores. O que é que nós, de facto, fizemos aqui?" Imediatamente de seguida, Frege reformula a pergunta pela negativa: "Ou, para 
começar: o que é que nós não fizemos? Não fizemos uma lista de propriedades para depois dizer: criamos uma coisa que verifica estas propriedades". De acordo com Frege, o que fizemos foi reconhecer que há qualquer coisa em comum entre duas funções que tomam os mesmos valores para cada o objeto e chamar a esse algo em comum o curso de valores das duas funções. O direito de proceder assim é-nos dado, segundo Frege, por uma lei básica da lógica: o direito de converter a generalidade duma igualdade numa igualdade (identidade). Por outras palavras, o direito a converter a generalidade que exprime a igualdade dos valores tomados por duas funções, numa identidade entre objetos (entre os cursos de valores dessas funções). Frege insiste: "Podemos chamar de criação a este procedimento? A discussão desta questão pode facilmente degenerar numa altercação sobre palavras". Seja como for, conclui Frege, a existência de cursos de valores incorpora, através dum único princípio (e duma vez por todas), o que é necessário para erigir o material das Grundgesetze der Arithmetik. Em vez de dar justificações ad hoc da existência de entes matemáticos sempre que deles necessitamos, com os cursos de valores estamos na posse dum procedimento universal. O leitor coevo há-de reconhecer aqui uma precoce declaração do papel fundamental da teoria dos conjuntos na matemática como tribunal da existência de entes matemáticos.

A primeira passagem em que Frege discute a existência de cursos de valores, é uma variação deste tema da universalidade. A existência de entes matemáticos converge para um só ponto: a existência de cursos de valores. Por isso "tanto quanto me é dado ver, uma disputa [acerca duma falha nas Grundgesetze der Arithmetik] apenas pode ocorrer no que diz respeito à minha lei básica de curso de valores $(\mathrm{V})$. [...] De qualquer modo, marca-se aqui o lugar onde se tem de tomar uma decisão". A decisão de Frege foi a de aceitar cursos de valores (e, portanto, extensões de conceitos). As extensões são objetos e nunca são confundidas nas Grundgesetze der Arithmetik com conceitos. Frege continua firmemente a submeter-se à terceira injunção. Porém, agora cada conceito tem um procurador no domínio dos objetos: a sua extensão. Como é sobejamente conhecido, isso é fatal. Depois da célebre carta de Russell a comunicar-lhe o paradoxo, Frege ainda foi a tempo de escrever um posfácio no segundo volume das Grundgesetze der Arithmetik. A seguinte passagem do posfácio é elucidativa: "Teria ficado feliz em ter dispensado esta fundamentação [extensões] se tivesse sabido dum substituto para ela. Mesmo agora, não vejo como é que a aritmética pode ser cientificamente fundamentada, como é que os números podem ser apreendidos como objetos lógicos e postos em consideração se não for permissível [...] passar dum conceito para a sua extensão".

Desde o início do seu projeto de redução da aritmética à lógica, desde Os Fundamentos da Aritmética, Frege tentou evitar extensões. Na época d'Os Fundamentos da Aritmética, Frege ainda parecia alimentar a esperança de que as poderia dispensar. Finalmente, nas Grundgesetze der Arithmetik, resigna-se pragmaticamente a elas.

\section{Notas e referências}

Aproveitando a minha presença em 2017 no XVII Encontro Brasileiro de Lógica em Pirenópolis (estado de Goiás), o professor Nelson Gomes convidou-me a visitar Brasília e a dar um seminário na universidade. Quero aqui agradecer-lhe o convite e, em especial, o ter-me mostrado a cidade. Não podia ter tido um cicerone mais bem informado e mais agradável do que o professor Gomes. A 12 de maio fiz a referida comunicação ao Seminário Permanente "Lógica no Avião" da Universidade de Brasília. A palestra intitulou-se 
"Ziguezague e a aritmética de Frege". Na sequência desse seminário, o professor Alexandre Costa-Leite endereçou-me um convite para escrever um artigo. Porém, o material de que falei no seminário já estava comprometido para outra publicação, tendo entretanto saído à estampa em

Zigzag and Fregean arithmetic. In: "The Philosophers and Mathematics", organizado por H. Tahiri. Logic, Epistemology, and the Unity of Science 43, Springer International, 2018, pp. 81-100.

Contudo, aceitei o convite do professor Costa-Leite e resolvi escrever o artigo que o leitor tem agora entre mãos. Debruço-me sobre os pontos do logicismo fregiano onde Frege é hesitante e menos claro. É, geralmente, nos pontos incertos do trabalho dum filósofo que recompensa um estudo mais atento. Muitas das observações que aqui faço são conhecidas e resisti a elaborar desenvolvimentos que surgiram naturalmente das considerações que discuto. O leitor interessado em mais informações e em referências bibliográficas pertinentes pode consultar a minha entrada "Logicismo" no Compêndio em Linha de Problemas de Filosofia Analítica, disponível em

http:/ / compendioemlinha.letras.ulisboa.pt/logicismo-fernando-ferreira/

No presente artigo, fiz numerosas referências a dois trabalhos de Frege: ao Die Grundlagen der Arithmetik e aos dois tomos das Grundgesetze der Arithmetik. Para o primeiro trabalho, usei a seguinte tradução para o português:

Os Fundamentos da Aritmética. Tradução, prefácio e notas de António

Zilhão. Imprensa Nacional-Casa da Moeda, Lisboa, 1992.

Para os dois tomos das Grundgesetze der Arithmetik usei a seguinte tradução para o inglês:

Basic Laws of Arithmetic. Tradução e edição de Philip A. Ebert e Marcus Rossberg. Oxford University Press, 2013.

As traduções para o português das Grundgesetze der Arithmetik são minhas, a partir do inglês acima. Listo, de seguida, os lugares onde o leitor pode encontrar as passagens citadas no texto:

"mais do que ter tornado verosímel ...", §90, Fundamentos.

"o conteúdo de um juízo de reconhecimento", §106, Fundamentos.

"se a Inglaterra é o mesmo ...", §66, Fundamentos.

"Falta-nos o conceito ...", §66, Fundamentos.

"se este conhecido conquistador ...", §56, Fundamentos.

"pressupusemos como conhecido ...", §107, Fundamentos.

"Embora eu seja ...", §68, Fundamentos.

"como é que apreendemos ...", posfácio, vol. 2, Basic Laws.

"só seguindo este princípio ...", §106, Fundamentos.

"sem [cursos de valores] não ...", prefácio, X, vol. 1, Basic Laws.

"Agora, como é que se resolve ...", §10, vol. 1, Basic Laws.

"O matemático, tal como o geógrafo ...", §96, Fundamentos.

"pode ser apontado ...", §146, vol. 2, Basic Laws.

"Podemos chamar ...", §147, vol. 2, Basic Laws.

"Tanto quanto me é dado ver ...", prefácio, VII, vol. 1, Basic Laws.

"Teria ficado feliz ...", posfácio, vol. 2, Basic Laws. 